\title{
Decisionismo e Hermenêutica Negativa: Carl Schmitt, Hans Kelsen e a afirmação do poder no ato interpretativo do direito ${ }^{1}$
}

\section{Decisionism and Negative Hermeneutics: Carl Schmitt, Hans Kelsen and the affirmation of power in the legal interpretative act}

\author{
Andityas Soares de Moura Costa Matos \\ Universidade Federal de Minas Gerais, Belo Horizonte - MG, Brasil \\ Diego Antonio Perini Milão \\ Universidade Federal de Minas Gerais, Belo Horizonte - MG, Brasil
}

\begin{abstract}
Resumo: O presente artigo pretende refletir sobre as teorias da interpretação jurídica nas obras de Carl Schmitt e Hans Kelsen, demonstrando que, muito embora assumam diferentes sentidos do decisionismo, essas teorias acabam por gerar uma hermenêutica negativa. Para tanto, analisa-se a obra de Schmitt nos anos de 1910, período ainda marcado por um enfoque neokantiano; nos anos de 1920, no contexto da crise de Weimar; e nos anos de 1930, quando Schmitt adere ao nacional-socialismo. No que diz respeito a Kelsen, privilegia-se as duas edições da Teoria Pura do Direito (1934 e 1960). Como conclusão, percebe-se a insuficiência da hermenêutica negativa.
\end{abstract}

Palavras-chave: Interpretação Jurídica. Hans Kelsen. Carl Schmitt. Aplicação do Direito. Poder.
Abstract: This paper intends to reflect upon the legal interpretation theories presented by Hans Kelsen and Carl Schmitt. It demonstrates that, however assuming different senses of decisionism, they end up generating a negative hermeneutics. For that, the theories made by Schmitt are analised in the 1910 years, period still characterized by a neokantian focus; in the 1920's, in the crisis of Weimar; and in the 1930's, when Schmitt had accepted the national-socialism. About Kelsen, the paper discusses the two editions of Pure Theory of Law (1934 and 1960). As a conclusion, it is possible to affirm the insuficiency of the negative hermeneutics.

Keywords: Legal Interpretation. Hans Kelsen. Carl Schmitt. Law's Application. Power.

\footnotetext{
${ }^{1}$ Recebido em: $12 / 07 / 2013$

Revisado em: 29/10/2013

Aprovado em: 1\%/11/2013
} 


\section{Introdução}

As recentes decisões do Supremo Tribunal Federal (STF) sobre a possibilidade de união estável homoafetiva (ADI n. 4277 e ADPF n. 132) e, também, acerca do aborto de fetos anencéfalos (ADPF n. 54) deram ainda mais relevo às discussões acadêmicas relativas ao eterno dilema da Teoria Geral do Direito, convertido em problema autônomo da Hermenêutica Jurídica, e que diz respeito aos limites da decisão judicial - se é que existem - diante do ordenamento jurídico positivo, repercutindo não apenas no campo hermenêutico, mas, sobretudo, no da validade e aplicação do direito. Apesar das atuais análises sobre o tema, na maioria das vezes, partir de um enfoque pós-positivista ou jusmoralista, baseando-se na teoria da argumentação de Robert Alexy e na ideia do direito como integridade de Ronald Dworkin, ${ }^{2}$ não será a abordagem específica do presente trabalho.

Ao que parece, a discussão interpretativa pode ser dirigida para o que Carl Schmitt chamou de "os três tipos de pensamento jurídico", a saber: normativismo, decisionismo e ordem concreta, conforme exposto em seu influente artigo de 1934, Über die Drei Arten des Rechts-wissenschaftlichen Denkens (SCHMITT, 2001b). Assim, pretende-se realizar um estudo da decisão judicial a partir das obras de Hans Kelsen e de Carl Schmitt, contrapondo - em cada autor e entre eles - uma teoria da validade do direito a uma teoria da aplicação/interpretação jurídica, sublinhando inclusive as possíveis continuidades e descontinuidades no diálogo entre ambos os pensadores. A escolha desses dois autores em detrimento de outros tidos como mais "atuais" se deve não apenas ao fato de eles serem clássicos, mas deriva fundamentalmente da percepção que ambos tinham de sua época, que, em muitos sentidos, se assemelha à nossa, na qual o Poder Judiciário é chamado a "pôr peias" - ou a "se unir", como ocorreu

\footnotetext{
2 Apesar de nosso posicionamento, é preciso observar que há divergência em classificar o pensamento desses autores, sobretudo de Dworkin, como pós-positivista. Assim, por exemplo, Luis Prieto Sanchís classifica Dworkin como jusnaturalista (SANCHÍS, 2009, p. 423-425), enquanto Alfonso García Figueroa prefere ver nele apenas um antipositivista, sem ligá-lo especificamente ao pós-positivismo. (FIGUEROA, 2009, p. 216)
} 
durante o III Reich - ao Poder Executivo, buscando assim vencer (Kelsen) ou aprofundar (Schmitt) a exceção.

Tanto Hans Kelsen como Carl Schmitt desenvolvem seus pensamentos pautados na distinção entre direito e poder, ou seja, ambos realizam um imenso esforço teórico para não identificar o direito com a "lei da selva", pretendendo não reduzir a validade do ordenamento jurídico à vontade do mais forte. Desse modo, o mestre da Escola de Viena e o jurista da exceção colocam-se contra o positivismo imperativista - dominante no século XIX - de autores como Bentham e Austin.

Para tal corrente positivista, o direito derivaria do mero fato de quem tem mais força para impor sua vontade, fazendo cumprir seus comandos a partir da aplicação de um castigo. Dessa forma, o poder seria anterior ao direito e esse estaria reduzido a atos de simples violência. Diante do exposto, as posteriores ideias de decisionismo em Carl Schmitt e de norma hipotética fundamental em Hans Kelsen terão funções semelhantes, ao menos quanto ao fim a que se destinam: demonstrar que o direito é algo diverso do poder, tornando possível apreender e visualizar em separado tais realidades. Todavia, devido à complexidade do tema relativo à identidade - ou não - entre direito (Recht), poder (Macht) e violência (Gewalt), esta abordagem se limita à apresentação crítica das doutrinas hermenêuticas de Schmitt e Kelsen, apresentando suas várias versões, fraturas e acertos, entendendo que surgem com o objetivo - alcançado ou não, o que não nos importa neste artigo - de impedir a identificação pura e simples entre normatividade e facticidade.

Desse modo, nas duas primeiras seções deste artigo serão analisadas, respectivamente, as teorias da interpretação de Carl Schmitt - em seus três momentos, quais sejam, em Weimar nos anos de 1910 e 1920 e, já no contexto do III Reich, nos anos de 1930 - e de Hans Kelsen - tendo em vista as duas edições da Teoria Pura do Direito, em 1934 e 1960 -, concluindo-se o texto com a resposta à questão que lhe dá título, quando se procurará demonstrar o sentido, as semelhanças e as diferenças entre o decisionismo absolutista da exceção característico do pensamento de Schmitt e o decisionismo relativista judicial que deflui da visão de mundo de Hans Kelsen. 


\section{As Teorias da Interpretação Jurídica em Carl Schmitt}

Nesta seção, a obra de Schmitt sobre a aplicação do direito será analisada em três momentos: nos anos de 1910, período ainda marcado por um enfoque neokantiano; nos anos de 1920, no contexto da crise de Weimar; e nos anos de 1930, quando Schmitt adere ao nacional-socialismo.

\subsection{Considerações Gerais}

É em meio a análises não propriamente sobre a aplicação do direito, mas sobre a criação, a validade e a essência do ordenamento jurídico, que surge a contenda sobre a correta decisão judicial, que terá lugar na obra schmittiana de 1912, Gesetz und Urteil: eine Untersuchung zum Problem der Rechtspraxis (Lei e Juízo: Uma Investigação Sobre o Problema da Prática Jurídica). Deve-se ressaltar que, em Gesetz und Urteil, o tema da decisão, em um sentido amplo, ainda é tratado por Schmitt no campo prático, ou seja, tendo em vista a aplicação do direito por uma autoridade judicial, permitindo assim a abordagem de uma verdadeira teoria da interpretação jurisdicional. Porém, nas obras posteriores do jurista o tema da decisão se desloca do campo da interpretação para o da validade e criação do direito, constituindo seu fundamento e adquirindo um específico significado conceitual. Já em Hans Kelsen, a decisão sempre é abordada como parte integrante de uma teoria da aplicação/interpretação, sendo ela considerada elemento político e não jurídico.

Apesar desse dualismo entre teoria da validade e teoria da aplicação/interpretação, ver-se-á até que medida, em cada um dos dois autores, os postulados de um campo influenciam nos pressupostos metodológicos do outro, bem como as consequências de tal comunicação - ou ausência de comunicação - para a coerência interna de tais teorias.

\subsection{Teses Sobre a Interpretação no Período do Estado de Direito}

Carl Schmitt, ao contrário do posicionamento defendido em sua fase de "maturidade" - expressa nas obras Politische Theologie (Teologia Política, 1922) e Der Begriff des Politischen (O Conceito do Político, 
1927; 1932) -, em Gesetz und Urteil $(1912)^{3}$, orienta o seu raciocínio com base na ideia de que todo Estado constituí-se como Estado de Direito, algo bastante similar ao que fará Kelsen durante toda sua obra. Porém, o jurista alemão já demonstra estar tocado, ainda que de forma muito diversa e superficial, com aquilo que será o grande mote de todo seu pensamento: a exceção.

Para Schmitt, o normativismo kelseniano - a ideia de uma autonomia científica máxima do direito, em que uma norma somente encontraria sua origem a partir de outra norma e nunca em um fato - levaria ao consequente entendimento, para manter a coerência da citada teoria da validade, de que uma decisão judicial só pode ser entendida como correta quando estiver em conformidade com a lei. ${ }^{4}$ Assim, Schmitt entende que

[...] numa situação excepcional, num caso para cuja resolução não é possível apontar uma disposição normativa normalmente aplicada pelo juiz, a decisão manifesta-se imediatamente como irredutível à lei, não podendo o momento fáctico do juízo, o momento próprio da prática jurídica, ser nela subsumido. (FRANCO DE SÁ, 2006, p. 74 , grifos do autor)

3 Uma vez que esse livro de Schmitt não está traduzido para o português, utilizar-se-á nesta seção do artigo a tradução de alguns de seus principais trechos contidos na obra de Franco de Sá (2006), que é, aliás, a mais completa introdução em língua portuguesa ao pensamento integral de Schmitt, da juventude à velhice.

4 "Quando é que uma decisão judicial é correcta? Na maior parte das vezes, ela é tida como correcta se for "conforme à lei", se corresponder ao direito positivo vigente. Ao erguer a conformidade à lei de uma decisão como critério da sua correcção, toma-se como ponto de partida o vínculo do juiz à lei. A resposta à pergunta pela correcção de uma decisão dar-se-ia assim, para o jurista, o mais facilmente possível quando a lei prescreve inequivocamente ao juiz julgar um muito determinado estado de coisas de um determinado modo. Se houvesse uma prescrição legal positiva que ordenasse ao juiz manter-se rigorosamente na literalidade da lei e no uso da linguagem da vida diária, e não decidir nenhum caso que não fosse indubitavelmente regulado através de uma lei, então estaria fundada a maior probabilidade de que todas as decisões judiciais fossem correctas. Mas uma tal lei conteria a sua própria refutação, ao acabar autenticamente por ordenar ao juiz decidir apenas quando estiver seguro de decidir correctamente, recusando em caso de dúvida a decisão. Com aquele "ideal" de uma prática conforme à lei não seria muita coisa ganha, porque, como é evidente, são precisamente os casos de dúvida que são tanto de interesse científico como prático". (SCHMITT apud FRANCO DE SÁ, 2006, p. 73) 
Diante do problema da interpretação, Carl Schmitt - já em resposta a Hans Kelsen e à pretensão de pureza da ciência do direito defendida na sua tese de livre-docência Hauptprobleme der Staatsrechtslehre (Problemas Capitais da Teoria Jurídica do Estado, 1911) - inicia sua obra Gesetz und Urteil: eine Untersuchung zum Problem der Rechtspraxis (1912) com a seguinte proclamação:

O presente tratado coloca-se a questão de saber quando uma decisão resultante da prática jurídica é correcta, e responde-lhe indicando que é a própria prática jurídica que decide sobre isso. ( $\mathrm{SCH}-$ MITT apud FRANCO DE SÁ, 2006, p. 72)

O tema da aplicação do direito, especificamente em uma decisão judicial, é, na referida obra, tratado por Schmitt não como um assunto propriamente de interesse central, mas muito mais como um argumento-chave para a tese de que o direito, apesar de não se identificar com o fático - o que configuraria uma visão reducionista - não independe de modo completo dessa esfera. Nesse sentido, como salienta Franco de Sá, Schmitt opõe-se a Kelsen porque ele leva ao extremo a separação kantiana entre ser e "dever-ser", o que inspira Schmitt a questionar a pureza da ciência do direito frente à prática jurídica, uma vez que não entende a conformidade da lei como critério para a correta decisão judicial. (FRANCO DE SÁ, 2006, p. 72-75)

Porém, a recusa do jurista germânico em caracterizar a correta decisão judicial como uma simples operação de conformação à lei não identifica a teoria da interpretação schmittiana de 1912 com o realismo jurídico norte-americano, pautado por um forte sentido subjetivo do juiz. O que Carl Schmitt partilha com o realismo é, na verdade, uma aguda percepção que identifica o problema da interpretação legalista na desconsideração do caráter geral sob o qual as normas jurídicas são formuladas, abrangendo somente a normalidade dos casos em um processo lógico-dedutivo de cariz matemático e mecanicista.

Todavia, diante da irredutibilidade do direito ao fático, Schmitt não identifica por completo sua teoria da validade com sua teoria da aplicação, ou seja, não admite que somente a decisão do juiz seja o que põe 
o direito. Desse modo, Schmitt se diferencia dos realistas na medida em que não promove uma exclusiva valorização do campo prático como fundamento do Direito, não tendo a intenção de justificar uma arbitrariedade, Schmitt não abre mão de um padrão objetivo. Apesar de a teoria da interpretação schmittiana de 1912 não antecipar a tese central do realismo norte-americano, é possivel identificar, no contexto da problemática do caráter genérico da lei e de casos concretos excepcionais que necessitam de uma decisão judicial, o gérmen da discussão hermenêutica entabulada entre Herbert Hart e Ronald Dworkin sobre os hard cases. Uma vez negada a arbitrariedade, a discussão interpretativa volta-se agora para a discricionariedade e seus limites, inclusive ético-morais. A abertura prática para a decisão judicial dos hard cases - ou, na terminologia schmittiana de 1912, dos "casos excepcionais" - promovida por Schmitt poderia se resolver, a exemplo do que fez Hart, em uma discussão sobre o poder discricionário do juiz ou, por outro lado, poderia trazer à luz uma questão ética, devendo o juiz observar certos pressupostos para a correta decisão, com o que Schmitt teria antecipado certos elementos do raciocínio de Dworkin.

Para o jurista alemão,

[...] uma decisão judicial é hoje correcta quando se deve assumir que um outro juiz teria decidido do mesmo modo. "Um outro juiz" significa aqui o tipo empírico do jurista moderno erudito em direito. (SCHMITT apud FRANCO DE SÁ, 2006, p. 76)

De acordo com Franco de Sá, Schmitt pretende tornar possível a construção de um juiz referência, de um "outro juiz" (typus) que servirá como padrão de conduta para o juiz que efetivamente aplica o direito em um caso concreto, guiando-o, assim, para uma correta decisão. (FRANCO DE SÁ, 2006, p. 76)

A base do raciocínio de Dworkin é muito semelhante àquela utilizada por Carl Schmitt na sua teoria da interpretação de 1912, principalmente no que diz respeito à criação de uma norma interpretativa diferenciada da norma positiva, quer dizer, no caso schmittiano, na exigência da decisão judicial estar de acordo com a interpretação do chamado "juiz-tipo", 
que de alguma maneira pode ser remetido à ideia dworkiniana de integridade do direito e à pressuposição de um "juiz Hércules". No entanto, ao contrário de Dworkin, Carl Schmitt não utiliza elementos externos, tal como uma ideia definida de justiça, para criar as normas de interpretação, o que, nesse ponto, distanciaria as ideias de Schmitt das de Dworkin ao mesmo tempo em que as aproximaria do institucionalismo: o "outro juiz" (ou o "juiz-tipo") de Schmitt, como norma de interpretação, está longe de representar a atitude interpretativa de uma comunidade que expressa e realiza a justiça, mas, por outro lado, não deixa de caracterizar o direito, de certa forma, sob o viés de uma visão institucionalista. Em conclusão: Carl Schmitt, já em 1912, retira dos juízes o papel de criação do direito: “[...] o juiz não é nenhum legislador. [...] Ele não cria nenhum direito, mas remete-se ao direito". (SCHMITT apud FRANCO DE SÁ, 2006, p. 80)

$\mathrm{Na}$ teoria do primeiro Schmitt, a instituição representaria o papel funcional que a integridade tem no pensamento de Dworkin. O institucionalismo costuma ser vinculado a uma terceira fase da obra schmittiana - desenvolvida nos anos de 1930, época em que o autor aderiu ao partido nacional-socialista alemão - principalmente porque serviu de inspiração para o pensamento da ordem concreta. É importante esclarecer, portanto, que, ao identificar um caráter institucionalista no pensamento schmittiano de 1912, isso não se refere especificamente à ordem concreta, mas sim a elementos gerais do institucionalismo. Observa-se que a teoria da interpretação judicial de Schmitt retratada em Gesetz und Urteil levará, não ao desenvolvimento do pensamento jurídico da ordem concreta, mas sim à teoria jurídica característica do decisionismo. Dessa forma, em 1914, no trabalho Der Wert des Staates und die Bedeutung des Einzelnen ( $\mathrm{O}$ Valor do Estado e a Importância do Indivíduo), o tema da decisão passa do âmbito da aplicação do direito para o da sua criação e validade/legitimidade, muito embora o pressuposto de que todo Estado é necessariamente Estado de Direito seja ainda mantido. Schmitt continua defendendo a tese de uma não identificação total entre fato e direito. O foco deixa então de ser a figura do juiz e passa a ser a figura do legislador que, por meio da decisão - ou melhor, de um decisionismo - faz a mediação - nos moldes platônicos - com um "direito natural sem naturalismo" que, em outras 
palavras, dá conteúdo (histórico) à forma jurídica (ideal), como sintetiza Franco de Sá.

De certo modo, diante da ausência do papel criador do juiz, no primeiro Schmitt há uma decisão judicial sem decisionismo, pois tal termo diz respeito à capacidade de pôr o direito mediante uma decisão, ou seja, relaciona-se ao campo da validade e não ao da aplicação. Diante dos três tipos de pensamento jurídico que Schmitt reconhece, tal conclusão só reforça o nosso entendimento de um viés institucionalista já presente de maneira embrionária na teoria da interpretação judicial schmittiana de 1912.

\subsection{Teses sobre a Interpretação no Período da Exceção}

A discussão schmittiana entre direito e poder não se restringe apenas aos textos dos anos de 1910, continuando ao longo de toda a sua obra. Porém, em 1921, com o livro Die Diktatur (A Ditadura), surgem os primeiros indícios de uma significativa mudança de entendimento sobre a relação entre esses dois objetos de estudo. A distinção entre ditadura soberana e ditadura comissária contida nessa obra remete à discussão sobre a possibilidade de uma previsão legal, ou melhor, de uma previsão constitucional do estado de exceção, a exemplo do que acontece no artigo 48 da Constituição de Weimar.

Para Schmitt, apenas a ditadura comissária comportaria uma previsão legal, já que tem intuito reformista, pretendendo garantir e preservar a ordem jurídica vigente por meio de sua suspensão, ao contrário da ditadura soberana, de viés revolucionário, que objetiva construir uma nova ordem. Neste último caso, uma previsão constitucional da ditadura soberana seria algo ilógico, já que prever é também, ao menos teoricamente, limitar. Desse modo, Schmitt afirma que o estado de sítio e outros institutos semelhantes do Direito Constitucional não passam de formas procedimentais falidas que pretendem delimitar a exceção e obscurecer sua real dramaticidade, pois na situação excepcional o direito é confrontado com sua origem violenta, não normatizada e inormatizável, muito embora sua missão seja, paradoxalmente, normalizar conflitos sociais. Schmitt demonstra assim que, por planejar normalizar todos os aspectos do real, 
o Estado Liberal inclusive tentou conferir contextura normativa ao estado de exceção (SCHMITT, 2009a, p. 221-263). Ora, por sua própria natureza a exceção é imune à normatização prévia, tratando-se antes de uma situação anômala que se põe entre o fato bruto e a norma jurídica.

O intuito limitador da previsão constitucional da ditadura comissária, retratada pela possibilidade de um estado de exceção, não encontra correspondência com a prática, sendo ineficaz. Com efeito, aquele que foi dotado de competência legal para executar o estado de exceção detém ampla margem interpretativa, tratando-se nesse caso não de uma mera aplicação lógico-dedutiva de dispositivos constitucionais, mas sim de um verdadeiro decisionismo. Diante disso, Schmitt iniciará sua famosa obra de 1922, Politische Theologie, dizendo que "[...] soberano es quien decide sobre el estado de excepción" (SCHMITT, 2009b, p. 13, grifos do autor). A verdadeira caracterização do poder soberano se dá na situação de emergência, dado que "[...] quien domine al estado de excepción, domina con ello al Estado, porque decide cuándo debe existir este estado y qué es lo que la situación de las cosas exige”. (SCHMITT, 2009b, p. 49)

O problema da interpretação que, em 1914, havia sido remetido do âmbito judicial para o campo legislativo, é agora, em 1922, transferido para o âmbito do estado de exceção. Porém, o tema da exceção, no ápice de sua formulação schmittiana, acarretará a primazia do político sobre o jurídico, ou melhor, embasará a anterioridade do poder em relação ao direito. Com isso e diante da afirmação schmittiana de que "[...] todos los conceptos centrales de la moderna teoría del Estado son conceptos teológicos secularizados [...]" (SCHMITT, 2009b, p. 17), o decisionismo sobre o estado de exceção, ao mesmo tempo em que elimina o dualismo platônico que fundamentava o direito na obra de 1914, estabelece um novo dualismo no pensamento de Carl Schmitt: a separação entre direito e Estado. Apesar de, nos seus primeiros escritos neokantianos, Schmitt ter defendido a prioridade do direito em relação ao Estado, ele muda radicalmente de posição a partir de Politische Theologie, eis que o Estado antecederia o direito, visto que somente nele se poderia tomar a decisão sobre a exceção, fundadora da ordem jurídica. 
Nos anos de 1920, Schmitt não aceita mais que todo Estado é Estado de Direito justamente devido à possibilidade de uma situação de exceção que objetiva suspender o ordenamento jurídico, enquanto o Estado permanece, até mesmo para realizar o futuro direito. O decisionismo assim estabelecido traz às claras uma teoria dualista do Estado e do direito, invertendo o anterior raciocínio de Schmitt sobre a relação entre direito e poder, com o que ele admite que o primeiro deriva-se do segundo, inaugurando a primazia do político. No entanto, essa é apenas uma das maneiras de compreender o pensamento de Schmitt nesse momento, existindo entendimento contrário no sentido de que o autor, nos anos de 1920, teria mantido a mesma fundamentação dualista dos anos de 1910. Para essa corrente, a decisão, por exercer um papel mediador, apenas estabeleceria o conteúdo de uma forma já existente, e assim o direito permaneceria independente do poder. Alexandre Franco de Sá é um dos adeptos dessa ideia, defendendo tal postura por meio da filosofia das ficções de Vaihinger, que Schmitt teria utilizado ao longo de sua obra. De qualquer maneira, esteja correta a primeira ou a segunda corrente, o certo é que no Schmitt dos anos de 1920 há pouco destaque para uma teoria da interpretação judicial, eis que todo seu interesse foi desviado para a discussão sobre a exceção, fenômeno que se radica majoritariamente no campo do Poder Executivo.

Muito embora a crítica ao normativismo permaneça presente nos escritos da segunda década do século XX, o que se constata nesse momento é a redução - quiçá a total negação - da capacidade interpretativa do juiz, uma vez que Schmitt, entendendo que o juiz é apolítico, considera que a aplicação do direito por ele realizada constitui-se apenas como uma derivação lógico-dedutiva da norma posta. Assim privado de vontade, o juiz schmittiano volta a ser, à semelhança do que ocorria na Escola da Exegese francesa, apenas a "boca da lei”. Na próxima seção deste artigo será possível ver como tal posição de Schmitt sofre uma contundente crítica de Kelsen, dirigida ao que ele chamou de "jurisprudência tradicional".

$\mathrm{Na}$ verdade, esse posicionamento surpreendentemente simplório de Schmitt é reflexo da dimensão que o decisionismo tomou em sua obra. Ao correlacionar intimamente os conceitos de decisão, soberania e estado de exceção com vistas à construção de uma teoria democrática plebisci- 
tária e antiparlamentar, Schmitt valoriza sobremaneira o Poder Executivo. Assim, para manter a coerência dessa nova tese, Schmitt restringe as funções do Poder Judiciário, eis que dar margem a um juiz para o exercício do controle de constitucionalidade significaria limitar o poder do soberano de decidir sobre o estado de exceção. De fato, o controle de constitucionalidade poderia recair sobre a decisão do Presidente do Reich, ameaçando-a em sua autonomia. Assim, para a teoria schmittiana não se tornar incoerente, a guarda da constituição precisa ser concedida ao mesmo Poder capaz de decidir sobre a exceção. Diante da necessidade de circunscrever a decisão na esfera política do Presidente do Reich - que, para Schmitt, seria "neutro", visto que eleito diretamente pelo povo, independentemente do jogo mesquinho dos partidos -, as funções dos demais poderes passam a ser minadas por Schmitt, impedindo a concorrência no ato da decisão.

A diferença relativa aos limites da interpretação judicial entre as obras da década de 1910 e as da década de 1920 fica ainda mais clara na seguinte afirmação de Schmitt: "[...] es improcedente atribuir a la Justicia ciertas funciones que rebasan el ámbito de una subsunción real, es decir, que traspasan las fronteras establecidas por la sujeción a normas de contenido preciso" (SCHMITT, 1998, p. 97). Mais uma vez, a teoria da interpretação de Carl Schmitt não é pensada de maneira autônoma, mas sim em função de um conceito de direito, ou seja, em função de uma teoria da validade. Schmitt constrói os limites da decisão judicial a partir do postulado central de sua teoria da democracia plebiscitária, que se relaciona ao decisionismo e à possibilidade sempre presente do estado de exceção. (SCHMITT, 1998, p. 113)

Dessa maneira, a capacidade interpretativa do juiz é limitada por Schmitt, dado que não há nenhum vínculo entre a categoria ontológica do povo homogêneo e o mero funcionalismo mecanicista do Poder Judiciário, ao contrário do que acontece com o Poder Executivo, que exerceria uma verdadeira "presentificação" do povo. Essa representação não se confunde com aquela liberal, de cariz contratual e privado, característica do Parlamento. Schmitt rejeita a representação parlamentar em nome da do Presidente, a única autoridade verdadeiramente representativa. O Presidente do Reich, escolhido por meio da aclamação, é o legítimo detentor 
do poder de decidir. Tal tese é radicalizada por Schmitt nos anos de 1930, quando passa então a apresentar não mais o Presidente do Reich, mas sim o Führer ${ }^{5}$ como o verdadeiro guardião e protetor do direito. Assim, a previsível redução do Poder Judiciário ao Executivo se completa na obra de Schmitt, sendo o Führer visto como juiz supremo (oberster Gerichtsherr) da nação alemã, detentor da "verdadeira judicatura". Por isso, o Führer não se sujeita à Justiça, sendo capaz de aplicar o direito sem mediações diante da emergência permanente que se tornou a regra na Alemanha a partir de 1933. Nas palavras de Schmitt. No panfleto Der Führer Schutz das Recht ( $O$ Führer Protege o Direito), Schmitt chega a dizer que o Führer, lançando mão de seu poder judicante, se autorizou a realizar uma justa vingança diante da "[...] peculiar deslealdade dos sublíderes do movimento [...]", superando, em nome do "bom direito alemão", a "[...] técnica puramente jurídica de conformidade ou não-conformidade legal [...]" que os inimigos do povo germânico tenderiam a identificar com o único procedimento correspondente ao Estado de Direito. (SCHMITT, 2001a, p. 224-225)

Dessa maneira, o resultado final da "hermenêutica" schmittiana consiste em negar todo poder de decisão aos juízes, vistos como seres apolíticos que apenas devem cumprir a vontade do povo, presentificada e garantida primeiro pelo Presidente do Reich e, ao final, pelo Führer, o supremo juiz da Alemanha. Isso equivale, por óbvio, a negar qualquer possibilidade hermenêutica, bem como a dispensar o juiz do fardo ético relativo à decisão. Para ser jurídica, basta que a decisão judicial se limite a revelar a vontade "democrática" do povo uno e homogêneo, não exigindo maior fundamentação, senão aquela já indicada de antemão pelo soberano.

5 O título de Führer era então totalmente inconstitucional na Alemanha. Na verdade, com a morte de Hindenburg, Presidente do Reich, em 2 de agosto de 1934, Hitler, que até então era Chanceler, declarou que ambos os cargos deveriam ser combinados, dando origem a uma autoridade suprema que controlava tanto as forças armadas quanto o Estado. (BENDERSKY, 2000, p. 114) 


\section{As Teorias da Interpretação em Hans Kelsen}

Nesta seção são discutidas as teses sobre interpretação jurídica presentes nas duas edições da Teoria Pura do Direito de Kelsen (1934 e 1960), por meio das quais se constrói e se destrói, com um mesmo gesto, a célebre "teoria da moldura".

\subsection{Considerações Gerais}

O primeiro pressuposto que se deve ter em mente na análise da teoria da interpretação de Hans Kelsen é que o normativismo kelseniano enquadra-se ideologicamente na versão do positivismo ético moderado, distinguindo-se da versão extremada, uma vez que para a primeira "[...] a norma jurídica não tem validade sacramental, absoluta ou indiscutível, sendo apenas um meio para se resguardar a ordem social" (MATOS, 2005, p. 29). Assim, apesar de ser um erro frequente entre os autores mais superficiais, o normativismo kelseniano não pode ser reduzido a um mero legalismo em que impera a literalidade indiscutível da lei. E é exatamente a teoria da interpretação de Kelsen que irá deixar clara tal opção metodológica, colocando-se contra a ideologia iluminista da subsunção que vê no juiz um mero operador lógico, personificado, nos termos de Montesquieu e Schmitt, como a "boca da lei".

Para Hans Kelsen, não há separação entre aplicação e criação do direito, muito embora ele desenvolva sua teoria da validade jurídica distinguindo-a de uma teoria da interpretação, a qual abrange aplicação e criação. Enquanto a teoria da validade pertence ao campo científico, a teoria da aplicação/interpretação se refere ao campo político, em que se insere a decisão que cria/aplica a norma. Tal se refere tanto à decisão do legislador quanto à decisão do juiz, pois para o mestre da Escola de Viena a aplicação do direito comporta dois momentos: um primeiro, de natureza cognitiva, e outro de caráter volitivo, desenvolvidos ambos com base em um esquema hermenêutico de molduras, como se verá adiante.

Desse modo, diferentemente da análise schmittiana sobre o normativismo, a teoria da interpretação de Kelsen não está pautada em uma mera análise lógico-dedutiva. Ao contrário, Hans Kelsen combate a Es- 
cola da Exegese, bem como qualquer outra que defenda o primado da lei sobre o juiz. No entanto, muitos críticos questionam se a natureza política da decisão judicial contaminaria a pretensão de pureza da teoria da validade kelseniana, uma vez que a criação/aplicação do direito pelo juiz promoveria o contato entre o campo da ciência autônoma do direito (dever-ser) e o campo da política, contato marcado pelo fato de poder ser, com o que seria desobservada a separação neokantiana entre ser e o "dever-ser" adotada por Kelsen.

A teoria da interpretação em Hans Kelsen pode ser dividida de modo sistemático em duas fases: a inicial, referente à primeira edição da Reine Rechtslehre (Teoria Pura do Direito) de 1934, e a final, relativa à segunda, e definitiva, edição da referida obra, datada de 1960. É a partir dessa divisão que o presente trabalho se orienta.

\subsection{A Interpretação como Conhecimento e Vontade em 1934}

Hans Kelsen, à semelhança de Carl Schmitt, reconhece que o normativismo gera certo grau de indeterminação na aplicação do direito positivado, dando margem à liberdade interpretativa do juiz. Porém, Kelsen afirma que isso não é motivo para se negar a possibilidade de uma formulação científica do direito com base na separação entre as esferas do "ser" e do "dever-ser", ou seja, a discricionariedade judicial não basta para comprovar que o fundamento último do direito residiria, não em uma norma, mas em um fato.

Nesse sentido, afastando-se do entendimento de Schmitt exposto em 1912, Kelsen não vê um vínculo necessário entre o normativismo, entendido como teoria da validade do direito, e a interpretação lógico-dedutiva (subsunção), entendida como teoria da aplicação do direito. Ao contrário, a indeterminação na aplicação do direito é abordada e solucionada pelo normativismo, que admite que o juiz exerce uma função de criação de normas jurídicas, agindo com o fito de complementar a ação criadora do legislador. Ao considerar o papel criador do juiz devido à indeterminação própria do caráter geral das normas, Kelsen admite a discricionariedade da decisão judicial; ao mesmo tempo, não exclui o normativismo como teoria da validade do direito, razão que o levará, na primeira edição 
da Teoria Pura do Direito de 1934, a elaborar sua teoria da aplicação/ interpretação do direito por meio de dois momentos, um cognitivo e outro volitivo, dado que "[...] indeterminação implica escolhas, as quais demandam atos de vontade que criam direito". (SANTOS NETO, 2012, p. 387)

O primeiro momento - cognitivo - é o que se liga diretamente ao normativismo. A norma a ser aplicada configura-se assim como uma moldura que delimitará a vontade do juiz, tornando o ato discricionário e não arbitrário. Nesse primeiro momento é necessário conhecer todas as possibilidades de interpretação permitidas pela indeterminação da norma (KELSEN, 2009, p. 76-79). O segundo momento - volitivo - liga-se diretamente à discricionariedade. $\mathrm{O}$ aplicador do direito deve escolher, a partir de sua vontade, uma dentre as várias interpretações possíveis identificadas no momento cognitivo, ou seja, dentre aquelas possibilidades compreendidas pela moldura normativa. (KELSEN, 2009, p. 81-82)

A escolha entre as interpretações compreendidas dentro da moldura está baseada pura e simplesmente na vontade particular do juiz, não sendo orientada por nenhuma norma interpretativa ou padrão de justiça externo ao direito, a exemplo de princípios vinculativos (Dworkin) ou da consideração de um "juiz-tipo" (Schmitt). Assim, o poder discricionário do juiz é intensificado na teoria da interpretação kelseniana, pois a escolha que embasa a decisão está pautada em valores particulares do aplicador do direito, não havendo uma "moral institucionalizada" ou pertencente ao direito que possa limitá-lo, ao contrário do que propõem pós-positivistas como Alexy. Segundo Kelsen, a consideração de elementos morais e valorativos próprios de cada julgador não compromete a Teoria Pura do Direito, já que tais elementos pertencem ao campo da aplicação, comportando um teor político que em nada influi na análise da validade das normas, que se dá mediante processos científicos desenvolvidos graças à ideia de derivação normativa dinâmica, a qual se liga à forma e não ao conteúdo do direito. Em Kelsen, validade não se confunde com criação/aplicação das normas jurídicas, ao contrário das posteriores correntes pós-positivistas que insistem em uma identificação entre esses dois elementos.

Essa posição inicial, defendida na primeira edição da Teoria Pura do Direito de 1934 (KELSEN, 2006, p. 115 et seq.), pode levar a um de- 
cisionismo moderado, já que o órgão aplicador do direito não encontra limites para sua atuação, a não ser o quadro traçado pelo cientista do direito. Mas mesmo essa frágil barreira cai por terra em 1960, na segunda e definitiva edição da Teoria Pura do Direito, na qual Kelsen reconhece que o juiz pode, mediante um autêntico ato interpretativo, decidir fora da moldura proposta pela ciência do direito.

\subsection{A Interpretação como Vontade em 1960}

Como visto no final da subseção anterior, a grande mudança da teoria da interpretação kelseniana de 1960 com relação à de 1934 foi a admissão da possibilidade de o juiz decidir também fora da moldura (KELSEN, 1998, p. 369-370). Desse modo, o papel criador do juiz não mais se limita a uma complementação da norma estabelecida pelo legislador, passando a ser dotado também de uma capacidade criadora inicial. Não há mais qualquer distinção qualitativa entre a liberdade do legislador e a liberdade do juiz. Agora ambos estão sujeitos ao mesmo grau de vinculação normativa material, ou melhor, à total ausência de vinculação material.

Com isso, na edição de 1960 da Teoria Pura do Direito, o momento cognitivo da interpretação é sobrepujado pelo momento volitivo. Segundo Arnaldo Bastos Santos Neto (2012, p. 397),

Kelsen desenvolve uma concepção meramente voluntarista da interpretação, admitindo a escolha, por parte do aplicador do direito, de uma opção que se encontre 'fora' da moldura. Além disso, recai em uma teoria cética da interpretação.

Parece significativo que o motivo pelo qual Kelsen reformula sua teoria da moldura resida em uma situação na qual a força e a violência determinaram, no contexto de uma decisão do Conselho de Segurança da Organização das Nações Unidas, uma interpretação que antes Kelsen julgara, na qualidade de cientista do direito, cientificamente impossível, quer dizer, localizada fora da moldura das interpretações possíveis (PAULSON, 1990, p. 147). A radicalização do Kelsen de 1960 não significa que a moldura deixou de existir, mas sim que ela pode ser continuamente ampliada por atos de vontade daqueles a quem a ordem jurídica 
confiou o poder de decidir. Em sentido prático, isso equivale a uma autorização para que qualquer decisão tomada pelo órgão competente seja válida. No limite, mesmo decisões flagrantemente contrárias ao ordenamento jurídico em questão podem ser efetivadas, caso não sejam utilizados os meios técnicos que o próprio sistema oferece para invalidá-las - recursos, ação rescisória, revisão criminal etc. - e elas venham a transitar em julgado. Kelsen admite então que uma decisão contrária ao ordenamento pode tornar-se juridicamente válida.

Parece que a abertura da moldura normativa realizada por Kelsen atende às bases metodológicas de seu pensamento, ou seja, está em consonância com o positivismo ético moderado e com a filosofia relativista, opondo-se a uma filosofia absoluta que se coloca contra a mutabilidade da ordem vigente. Aliás, é justamente por desconsiderar a existência de qualquer verdade absoluta - ou, ao menos, ter em vista a impossibilidade de seu conhecimento - que Hans Kelsen adotará, sob a óptica da ciência do direito, uma derivação normativa dinâmica para sua teoria da validade, estando mais uma vez de acordo com a mutabilidade da ordem social, entendimento calcado no relativismo filosófico típico do pensamento kelseniano. (KELSEN, 1998, p. 219)

Dessa maneira, o princípio dinâmico está relacionado diretamente à forma, opondo-se ao princípio estático, que diz respeito ao conteúdo. Porém, apesar desse nosso argumento, muito se critica a abertura kelseniana da moldura interpretativa, quando confrontada com os pressupostos da Teoria Pura do Direito. Para alguns críticos, a admissão de uma interpretação judicial fora da moldura colocaria em xeque a coerência da teoria da validade kelseniana, ou seja, a real sustentação do normativismo como fundamento científico do direito. ${ }^{6}$ Apesar de Kelsen considerar a

6 Nesse sentido, citem-se as posições de José Antonio Sanz Moreno e Marcelo Andrade Cattoni de Oliveira. O primeiro defende que na teoria da interpretação kelseniana “[...] todo acto jurídico es actuación política, que toda norma es ejercicio del poder. Cuando se termina afirmando que todo hecho productor de una norma jurídica es fruto de una decisión volitiva, la pretendida autonomía del derecho y de su ciencia es difícil de mantener" (MORENO, 2002, p. 176). Já o segundo afirma que "[...] aceitar como sendo interpretação do direito, sob o ponto de vista de uma teoria do direito - de uma ciência que descreve normas jurídicas e a dinâmica dessas normas jurídicas -, a possibilidade de 
decisão que aplica e cria o direito como algo pertencente ao campo político, estando assim separada da seara jurídico-científica - à qual a análise da validade do ordenamento pertence -, a aplicação do direito sem qualquer limite interpretativo acarreta o questionamento sobre a efetividade da distinção neokantiana entre "ser" e "dever-ser".

Tal leitura, muito próxima daquela que levou Carl Schmitt a desenvolver sua teoria da interpretação já em 1912, orienta-se, ao que nos parece, em torno de uma questão central: a teoria da interpretação de 1960 tornaria a teoria da validade de Hans Kelsen não um normativismo, mas sim um decisionismo nos moldes do realismo jurídico norte-americano? Se a fundamentação do direito, diante da ruptura com a coerência material do ordenamento jurídico - provocada pela decisão fora da moldura -, encontra sua origem no mero ato de vontade daquele que detém o poder, tal não deixaria de dar lugar, na verdade, a uma teoria imperativista do direito. Tal visão ganha ainda mais força se considerar o fato que levou Kelsen a mudar de opinião, qual seja, a vontade das potências que compunham o Conselho de Segurança da ONU na época da Guerra da Coreia. Nesse caso específico, a teoria do realismo jurídico encontraria íntima correspondência na teoria realista das relações internacionais, que considera a impossibilidade de um Leviatã no plano internacional ou, o que é o mesmo, a inexistência de um ordenamento jurídico global, dado que prevalece no cenário internacional a vontade do mais forte, ou melhor, a vontade que consegue se impor.

Em primeiro lugar, no que concerne à teoria da interpretação, é evidente que a abertura kelseniana da moldura se identifica com um realismo jurídico (SANTOS NETO, 2012, p. 399). No entanto, o realismo jurídico "puro" identifica validade e aplicação/interpretação do direito, o que, ao que nos parece, não ocorre em Kelsen justamente porque a vontade do criador/aplicador do direito, apesar de não reconhecer qualquer limite material, sobre uma regulação formal que somente o normativismo jurídico pode descrever de modo adequado. Com efeito, Kelsen costumava

produção de uma norma de escalão inferior ou a realização de um ato coercitivo que se processem fora do quadro das interpretações possíveis de uma norma superior aplicanda é, no mínimo, romper com o postulado metodológico de separação entre teoria e sociologia do direito, entre 'ciência normativa' e "ciência causal"'. (OLIVEIRA, 2012, p. 416) 
ironizar o realismo jurídico norte-americano - corrente que lhe parecia por demais naïve - argumentando que o juiz só pode dizer o que é direito porque antes foi classificado por esse mesmo direito como juiz; ou seja, para existir, o decisionismo judicial precisa de uma norma válida anterior que o constitua como tal, eis que somente aqueles autorizados pelo direito podem agir como seus órgãos de aplicação/criação. Desse modo, admite-se o caráter realista da teoria da interpretação kelseniana, mas nega-se um desdobramento puramente imperativista no conceito científico de direito desenvolvido por Kelsen.

Como já foi dito, a vontade do aplicador/criador do direito sofre uma regulação formal. Em outras palavras, há certos requisitos para que uma decisão seja expressão de uma interpretação jurídica autêntica. Um deles, por óbvio, é a constituição formal, feita pelo ordenamento jurídico, da autoridade judicial. Nesse sentido, a Teoria Pura do Direito busca identificar as autoridades existentes no ordenamento, tentando inclusive indicar a primeira autoridade histórica, assim como explicitar a maneira pela qual se confere autoridade aos demais escalões da pirâmide normativa. Trata-se, portanto, de uma análise formal da validade das normas, quer dizer, uma derivação normativa dinâmica que despreza o conteúdo e se resolve no problema da norma fundamental (Grundnorm), cujo desenvolvimento, contudo, escapa ao âmbito deste trabalho.

Segundo Kelsen, para ser vista como uma norma válida, certa vontade deve conter não apenas um sentido subjetivo de "dever-ser" (um "querer"), mas também um sentido objetivo de "dever-ser" (uma autorização). A ideia de "dever-ser" objetivo surge no pensamento kelseniano para combater a teoria imperativista, dado que sem essa construção nada distinguiria um comando jurídico de uma ordem advinda de um bando de salteadores de estrada, conforme a célebre imagem proposta por Santo Agostinho e desenvolvida criticamente no capítulo I da segunda edição da Teoria Pura do Direito.

Assim, a teoria da validade de Kelsen permanece pura, uma vez que, diante do relativismo axiológico que orienta o pensamento científico, a validade é tratada em âmbito formal. Por isso, entende-se que as críticas que insistem sobre uma suposta incoerência entre a teoria da inter- 
pretação e a teoria da validade de Kelsen devem ser ao menos atenuadas. Com efeito, enquanto a primeira teoria se desenvolve no campo material, a segunda abarca exclusivamente o campo formal. Ademais, mesmo nesse primeiro campo - qual seja, o da interpretação - há importantes considerações de natureza formal, eis que, como se viu, a autoridade criadora/ aplicadora precisa ser constituída segundo os ditames do ordenamento jurídico. Considerando que a atividade de criar/interpretar o direito liga-se majoritariamente - mas não exclusivamente - ao conteúdo e não à forma, é possível dizer dizer que a teoria da interpretação de Hans Kelsen exposta em 1960 comporta um decisionismo de viés realista que tem por condição uma teoria da validade normativista, a qual não sofre influência da prática jurídica.

Em segundo lugar, há de se reconhecer que o pluralismo e a abertura interpretativa de que hoje se abusa são totalmente conciliáveis com a hermenêutica kelseniana. Nela qualquer interpretação jurídica parece possível, bastando que seja posta pelo órgão competente para tanto. Isso significa que, ainda aqui, Kelsen não mascara o caráter violento do direito. Inexistindo valores necessários que limitem sua interpretação, o direito pode ser qualquer coisa que o poder queira. Mesmo que os diversos mecanismos técnico-formais característicos da ordem jurídica possam mascarar sua estrutura originalmente violenta, tal violência sempre ressurge, ainda que mediatizada, no momento da interpretação autêntica realizada pelos órgãos de aplicação/criação do direito que, pela própria natureza da experiência jurídica, precisam em certo momento proferir uma decisão última, a qual se fundará unicamente no poder final de decisão conferido a tais órgãos. Ora, tal poder é garantido pelo monopólio da violência de que goza a ordem jurídica.

Dessa maneira, o decisionismo hermenêutico de Kelsen não é uma limitação capaz de demonstrar a insuficiência de uma ciência pura do direito, mas sim um elemento que reforça o pano de fundo do qual o autor parte e ao qual retorna ao construir aquilo que se pode chamar de uma teoria negativa da interpretação: o direito é violência organizada e monopolizada, o que fica claro não apenas quando se considera sua origem (norma fundamental), mas também quando se visualiza sua contínua atualização hermenêutica mediante decisões que, ao fim e ao cabo, se fun- 
dem apenas na força imanente daqueles a quem o ordenamento concedeu o "poder-dever" de decidir de modo definitivo.

Para muitos críticos, o ponto de chegada radicalmente não hermenêutico da Teoria Pura do Direito demonstraria seu malogro. Todavia, somente pode pensar dessa maneira quem acredita que o direito deve ter algum conteúdo ou valor necessário, imponível ao intérprete no próprio ato interpretativo, limitando-o e proporcionando-lhe balizas. Todas as atuais teorias da argumentação jurídica, de Dworkin a Alexy, partem de tal premissa, postulando a existência de conteúdos jurídicos mínimos capazes de guiar a atividade interpretativa. Tal posição é insustentável para Kelsen, de modo que, ao invés de ser um fracasso, sua teoria da interpretação jurídica constitui o resultado lógico e necessário de todo o caminho percorrido pela Teoria Pura do Direito.

Postular uma interpretação aberta e sem qualquer controle material prévio significa, ao que parece, aceitar o caráter irracional - ou pelo menos não totalmente racionalizável - do direito. Ao dizer que o juiz pode estender a moldura hermenêutica antes traçada pela ciência jurídica, tornando-a inútil, Kelsen admite que o elemento fundamental do direito não é sua finalidade ou seu conteúdo - suas "verdades" -, mas a força que o aparelha: "auctoritas, non veritas, facit legem". Não por acaso, esse célebre dizer de Thomas Hobbes era um dos motes preferidos de Carl Schmitt, que aqui se aproxima de Kelsen, muito embora o decisionismo schmittiano se oriente primordialmente em relação ao Poder Executivo, enquanto Kelsen prefira localizá-lo na esfera de ação do Poder Judiciário, que é quem majoritariamente - mas não exclusivamente - diz o direito. Será direito aquilo que os órgãos de aplicação de determinado ordenamento jurídico disserem que é. Trata-se de uma visão bem pouco simpática, mas inegavelmente realista.

\section{Conclusão}

Comparando as teorias da interpretação schmittianas com as teorias da interpretação kelsenianas, é possível chegar a interessantes - e até mesmo irônicas - constatações. A primeira é a de que tanto Carl Schmitt 
como Hans Kelsen partem de um projeto semelhante, consistente na separação entre direito e poder. Como foi dito na introdução, não foi nosso objetivo analisar neste artigo o sucesso ou o insucesso desses respectivos projetos. Cabe apenas acrescentar que, embora Schmitt e Kelsen tenham partido de uma preocupação comum relativamente à separação entre direito e poder, ambos enveredaram por searas muito diferentes e mesmo opostas que, inclusive, muito cedo entraram em choque. Com efeito, enquanto o conhecimento do direito em Schmitt se dá por meio da decisão excepcional, Kelsen entende que a cognição jurídica se realiza normativamente, em última instância graças ao concurso da norma hipotética fundamental. Desse modo, no que compete a uma teoria do direito, tem-se um decisionismo em Carl Schmitt e um normativismo em Hans Kelsen.

No entanto, o mesmo não ocorre em suas teorias da interpretação. $\mathrm{Na}$ hermenêutica schmittiana de 1912, ao mesmo tempo em que se nega a teoria interpretativa lógico-dedutiva da subsunção, há também uma recusa do puro decisionismo, bem como uma tentativa de limitação da discricionariedade judicial, criando-se para tanto um padrão hermenêutico radicado na figura do "juiz-tipo", o qual representaria a função de uma norma interpretativa diversa da norma positivada, postura que antecipa em Schmitt uma teoria da validade jurídica de viés institucionalista. Já nas obras dos anos de 1920, Schmitt entende que o juiz, como órgão não político, deve se limitar a aplicar o direito por meio de simples subsunções, sendo que o papel criativo - que Kelsen sempre confiou também ao juiz - é transferido para a esfera do Poder Executivo, radicando-se primeiro no Presidente do Reich e, nas obras dos anos de 1930, no Führer, que assume então o papel de juiz-supremo da Alemanha. Em qualquer uma dessas leituras, Schmitt nega de maneira veemente o decisionismo judicial: seja porque existe um juiz-tipo a guiar a interpretação judicial (anos 1910), seja porque o juiz deve decidir mecanicamente como apolítica "boca da lei” (início dos anos de 1920), seja porque, finalmente, a efetiva decisão cabe ao chefe do Executivo, em suas duas versões: Presidente do Reich (Weimar, final dos anos de 1920) ou Führer (III Reich, anos de 1930). Desse modo, em Schmitt há uma decisão judicial sem decisionismo.

Hans Kelsen defende praticamente o inverso. Na teoria da interpretação de 1934, na qual o juiz precisa decidir dentro da moldura, Kelsen 
nega qualquer padrão moral, principiológico, ideal ou jurisprudencial para orientar a escolha de uma dentre as várias interpretações juridicamente possíveis. Tal escolha resolve-se como decisão pessoal e discricionária do julgador, não encontrando qualquer embasamento necessário no direito positivo ou na moral social vigente. Tem-se, portanto, o que chamamos de decisionismo judicial moderado. Todavia, em 1960, apesar de ser a ordem jurídica formal que habilita o juiz a decidir, Kelsen implode de vez qualquer pretensão hermenêutica, aduzindo que a decisão se dá de maneira incontrolada, já que o juiz pode decidir fora da moldura, ou seja, para além das opções "cientificamente" possíveis. Assim, em Kelsen há uma decisão judicial com decisionismo.

Ademais, além da peculiar aproximação que se verifica entre Kelsen e Hart e, de outro lado, entre Schmitt e Dworkin, a análise ora empreendida reforça nosso entendimento quanto à presença de um viés institucionalista na teoria da decisão judicial schmittiana de 1912. Tendo em vista que a discricionariedade não deixa de ser vontade, negar a existência de uma norma interpretativa fundada na instituição (expressa pelo "juiz-tipo") equivaleria a admitir a livre criação do direito pelo juiz, fato negado por Schmitt na obra de 1912.

Há, por fim, outra constatação mais interessante e ainda mais irônica, dado que o decisionismo judicial do Kelsen de 1960 exerce a mesma função do protodecisionismo schmittiano de 1914: conferir conteúdo à forma. Porém, enquanto no pensamento de Kelsen o decisionismo aplica-se apenas à teoria da interpretação, eis que dá conteúdo ao direito ao criá-lo/aplicá-lo de modo político, para Schmitt o decisionismo relaciona-se diretamente à teoria da validade do direito, eis que cabe à decisão excepcional atribuir conteúdo à ordem jurídica a ser restaurada (ditadura comissária) ou a ser posta (ditadura soberana). Assim, segundo Hans Kelsen, o direito como forma é obtido normativamente; já Carl Schmitt postula uma origem metajurídica para o direito, o que o leva, ao menos nas obras dos anos de 1910, a aderir a um dualismo de viés platônico que postula uma paradoxal categoria ontológica da forma - um "direito natural sem naturalismo" -, na qual o direito como decisão deve se encaixar. 


\section{Referências}

BENDERSKY, Joseph W. A history of nazy Germany. 2. ed. Chicago: Burnham, 2000.

FIGUEROA, Alfonso García. Criaturas de la moralidad: una aproximación neoconstitucionalista al derecho a través de los derechos. Madrid: Trotta, 2009.

FRANCO DE SÁ, Alexandre Guilherme Barroso de Matos. O poder pelo poder: ficção e ordem no combate de Carl Schmitt em torno do poder. 729f. Dissertação de Doutoramento em Filosofia. Coimbra: Faculdade de Letras da Universidade de Coimbra, 2006.

KELSEN, Hans. EI método y los conceptos fundamentales de la teoría pura del derecho. Tradução Luis Legaz Lacambra. Madrid: Reus, 2009.

KELSEN, Hans. Teoria pura do direito (edição de 1934). Tradução José Cretella Jr. e Agnes Cretella. São Paulo: Revista dos Tribunais, 2006.

KELSEN, Hans. Teoria pura do direito (edição de 1960). Tradução João Baptista Machado. São Paulo: Martins Fontes, 1998.

MATOS, Andityas Soares de Moura Costa. Filosofia do direito e justiça na obra de Hans Kelse $n$. Belo Horizonte: Del Rey, 2005.

MORENO, José Antonio Sanz. Ordenación jurídica y estado posliberal: Hans Kelsen y Carl Schmitt. Granada: Comares, 2002.

OLIVEIRA, Marcelo Andrade Cattoni de. Interpretação como ato de conhecimento e interpretação como ato de vontade: a tese kelseniana da interpretação autêntica. In: MATOS, Andityas Soares de Moura Costa; SANTOS NETO, Arnaldo Bastos. Contra o absoluto: perspectivas críticas, políticas e filosóficas da obra de Hans Kelsen. Curitiba: Juruá, 2012. p. 405-422.

PAULSON, Stanley. Kelsen on legal interpretation. Legal Studies, Bristol, v. 10, n. 2, 1990. 
SANCHÍS, Luis Prieto. Los principios como vehículos de la moral en el derecho. In: MOREIRA, Eduardo Ribeiro; GONÇALVES JÚNIOR, Jerson Carneiro; BETTINI, Lucia Helena Polleti (Org.). Hermenêutica constitucional: homenagem aos 22 anos do grupo de estudos Maria Garcia. Florianópolis: Conceito, 2009.

SANTOS NETO, Arnaldo Bastos. A teoria da interpretação em Hans Kelsen. In: MATOS, Andityas Soares de Moura Costa; SANTOS NETO, Arnaldo Bastos (Coord.). Contra o absoluto: perspectivas críticas, políticas e filosóficas da obra de Hans Kelsen. Curitiba: Juruá, 2012. p. 381-404.

SCHMITT, Carl. La defensa de la constitución. Tradução Manuel Sanchez Sarto. Madrid: Tecnos, 1998.

SCHMITT, Carl. La dictadura: desde los comienzos del pensamiento moderno de la soberanía hasta la lucha de clases proletaria. Tradução José Díaz García. Madrid: Alianza, 2009a.

SCHMITT, Carl. O Führer protege o direito. Tradução Peter Naumann. In: MACEDO JR., Ronaldo Porto. Carl Schmitt e a fundamentação do direito. São Paulo: Max Limonad, 2001a. p. 219-225.

SCHMITT, Carl. Sobre os três tipos do pensamento jurídico. Tradução Peter Naumann. In: MACEDO JR., Ronaldo Porto. Carl Schmitt e a fundamentação do direito. São Paulo: Max Limonad, 2001b. p. 161217.

SCHMITT, Carl. Teología política. Tradução Francisco Javier Conde y Jorge Navarro Pérez. Madrid: Trotta, 2009b. 
Andityas Soares de Moura Costa Matos é Graduado em Direito; Mestre em Filosofia do Direito; e Doutor em Direito e Justiça pela Faculdade de Direito da Universidade Federal de Minas Gerais (UFMG). Professor Adjunto de Filosofia do Direito e disciplinas afins na Faculdade de Direito da UFMG. Membro do Corpo Permanente do Programa de Pós-Graduação em Direito da Faculdade de Direito da UFMG. Diretor da Revista Brasileira de Estudos Políticos. E-mail: andityas@ufmg.br.

Endereço profissional: Av. João Pinheiro, 100, $11^{\circ}$ andar, Centro, Belo Horizonte, MG. CEP: 30130-180.

Diego Antonio Perini Milão é Graduado em Direito pela Universidade Estadual Paulista "Júlio de Mesquita Filho" (UNESP); Mestrando do Programa de PósGraduação em Direito da Universidade Federal de Minas Gerais (UFMG), orientado pelo Professor Doutor Andityas Soares de Moura Costa Matos. Bolsista do Conselho Nacional de Desenvolvimento Científico e Tecnológico (CNPq).. E-mail: dimilao@hotmail.com.

Endereço profissional: Rua Antônio Bento de Oliveira, n. 284, Centro, Nhandeara, SP. CEP: 15.190-000. 